Federal Reserve Bank of Minneapolis Research Department

\title{
Investment-Specific Technological Change, Skill Accumulation, and Wage Inequality
}

\author{
Hui He and Zheng Liu* \\ Working Paper 644 \\ Revised August 2007
}

\begin{abstract}
Wage inequality between education groups in the United States has increased substantially since the early 1980s. The relative number of college-educated workers has also increased dramatically in the postwar period. This paper presents a unified framework where the dynamics of both skill accumulation and wage inequality arise as an equilibrium outcome driven by measured investmentspecific technological change. Working through equipment-skill complementarity and endogenous skill accumulation, the model does well in capturing the steady growth in the relative quantity of skilled labor during the postwar period and the substantial rise in wage inequality after the early 1980s. Based on the calibrated model, we examine the quantitative effects of some hypothetical tax-policy reforms on skill accumulation, wage inequality, and welfare.
\end{abstract}

*He: Department of Economics, University of Hawaii; E-mail: huihe@hawaii.edu. Liu: Department of Economics, Emory University; E-mail: zheng.liu@emory.edu. We thank V.V. Chari, Larry Jones, Michele Boldrin, Nobu Kiyotaki, and Narayana Kocherlakota for helpful comments. We are grateful to Gianluca Violante for providing his data. Liu wishes to thank the Federal Reserve Bank of Minneapolis and the University of Minnesota for their hospitality. The views expressed herein are those of the authors and do not necessarily reflect the views of the Federal Reserve Bank of Minneapolis or the Federal Reserve System. 


\section{Introduction}

In the postwar period, the U.S. economy has experienced steady growth in per capita income, accompanied by substantial changes in income inequality. As shown in Figure 1, income inequality measured by the relative wage of college-educated workers (i.e., college wage premium) increased in much of the 1960s, then declined modestly in the 1970s, and has since increased substantially starting in the early 1980s. In the meantime, the number of skilled workers (e.g., those with college degrees) has steadily grown relative to the number of unskilled workers (e.g., those with high school diplomas), as is evident in Figure 2. Understanding potential causes of the observed dynamics in wage inequality and skill accumulation is of great interest to both academic economists and policy makers.

The literature on wage inequality is large and growing. Most studies attribute the dynamics of wage inequality to skill-biased technological change (SBTC). One possible mechanism through which SBTC may affect wage inequality is proposed by Katz and Murphy (1992). Based on a simple supply and demand framework, they argue that, if there is a constant secular trend in SBTC, then the increase in the relative supply of skilled workers in the 1970s associated with the baby boom generation leads to a temporary fall in inequality, which, before moving back to its secular trend, is bound to increase at an accelerated rate (see also Bound and Johnson, 1992). It is unclear, however, what drives the trend in SBTC. Acemoglu (1998) proposes that SBTC can be endogenous and can respond to the market size for skilled workers. As the relative supply of skilled workers increases, there will be a larger market size and more monopoly rents for skillcomplementary technologies. This provides a greater incentive for innovating firms to upgrade the productivity of skilled workers. As a result, the skill premium initially falls and then rises. ${ }^{1}$

Most studies in the SBTC literature do not examine the quantitative contributions of the underlying mechanisms that may drive wage inequality. Yet, to understand the driving mechanisms of the changes in inequality and other labor market phenomena, "it is necessary to formulate dynamic models that can quantitatively include the main alternative explanations so that one can measure the impact of each one of them" (Eckstein and Nagypál, 2004, p. 26).

In an important contribution, Krusell et al. (2000, henceforth KORV) build a quantitative framework to study the evolution of wage inequality. They show that, if capital equipments are more complementary to skilled workers than to unskilled workers (e.g., Griliches, 1969), then

\footnotetext{
${ }^{1}$ Other theories on wage inequality include, for example, openness to international trade, changes in the unionization rate, and changes in real minimum wages. A general consensus is that SBTC theories provide a more compelling story than these other theories. For a survey of this literature, see, for example, Acemoglu (2002) and Aghion (2002).
} 
variations in the quantities of input factors help account for much of the observed changes in college wage premium in the post-war U.S. economy. They interpret equipment-skill complementarity as a form of SBTC. They further suggest that the observed changes in capital equipments can be attributable to investment-specific technological change in the spirit of Greenwood, Hercowitz, and Krusell (1997, henceforth GHK). The study by KORV (2000) is particularly important from a macroeconomic perspective because it relates the driving forces of the relative demand for skilled workers and skill premium to input factors that can be explicitly measured.

A common feature of these SBTC-based theories - including KORV (2000) - is that technological change drives wage inequality through affecting the relative demand for skilled workers, taking as given the relative supply of skilled workers. ${ }^{2}$ In the current paper, we would like to turn the question around and ask: What quantitative framework helps account for the dynamics of both skill accumulation and wage inequality, taking as given some measures of SBTC? In other words, we would like to build a quantitative model with endogenous skill accumulation (instead of taking the supply of skills as given), and to examine whether the observed changes in wage inequality and the relative quantity of skilled workers can arise as an equilibrium outcome driven by measured technological change.

For this purpose, we build a general equilibrium model with vintage capital, in which production of capital equipments becomes increasingly efficient over time (as in GHK, 1997). To examine the quantitative effects of such capital-embodied (or investment-specific) technological change on the equilibrium dynamics of wage inequality and skill accumulation, we assume that capital equipments are more complementary to skilled workers than to unskilled workers (as in KORV, 2000), and that skill accumulation requires scarce resources and time (as in Ben-Porath, 1967; Trostel, 1993). With reasonable parameter values, we find that the model driven solely by measured investment-specific technological change is able to account for much of the steady growth in the relative quantity of skilled labor in the postwar U.S. economy, and the model does well in replicating the substantial rise in wage inequality after the early 1980s. Further, we find

\footnotetext{
${ }^{2}$ There are a few notable exceptions. For instance, Heckman, Lochner, and Taber (1998) develop and estimate an overlapping generations (OLG) model with heterogenous skills, endogenous (once-for-all) schooling choice, and post-school on-the-job investment to study college wage premium and skill formation. For their purpose, they approximate SBTC by a trend estimated from an aggregate technology, rather than using direct measures, such as that based on observed changes in the relative price of equipments. Greenwood and Yorukoglu (1997), on the other hand, emphasize the role of declining prices of producer durables and equipments in explaining the rise in wage inequality and the slowdown in productivity growth. Unlike KORV (2000), both of these studies abstract from capital-skill complementarity. For a more recent quantitative study of the changes in college wage premium and college enrollment rate, see He (2006), who constructs an OLG model that incorporates demographic change, investment-specific technological change, and capital-skill complementarity.
} 
that investment-specific technological change in our model accounts for about $52 \%$ of the average annual growth rate of output per hour during the postwar period, which is close to the finding in GHK (1997), who abstract from equipment-skill complementarity and skill accumulation.

Our model contains a simple mechanism that propagates the investment-specific technological change (denoted by $q$ ) to generate the observed patterns in skill accumulation and wage inequality. As $q$ grows over time, the relative price of capital equipments falls, which encourages investment in new equipments. Given equipment-skill complementarity, the expectation that the stocks of equipments will rise in the future provides incentive for increased investment in skill accumulation, since increases in equipments would raise the marginal productivity of skilled workers and lower the marginal productivity of unskilled workers and thereby drive up the skill premium. Of course, the increase in the relative quantity of skilled labor dampens the rise in the skill premium. With plausible equipment-skill complementarity and a calibrated skill accumulation process, the model is able to deliver both the steady growth in the relative quantity of skilled labor during the postwar period and the substantial rise in wage inequality after the early 1980s.

An implication of the model's mechanism is that, not only changes in $q$, but other factors that can raise the stocks of capital equipments can also raise wage inequality. To investigate this possibility, we present a counterfactual experiment based on the calibrated model. In the experiment, we lower the capital income tax rate from $39.7 \%$ to 0 in the spirit of the optimal Ramsey taxation literature (e.g., Chamley, 1986), and we examine the effects of this capitalincome tax reduction on skill accumulation and wage inequality. When we eliminate capital income taxes, we adjust the labor income tax rate to keep the present value of the tax revenue unchanged. We assume that the same time series for $q$ drives equilibrium dynamics before and after the tax reform. ${ }^{3}$ We also examine the effects of the tax reform on welfare, which is measured by a consumption equivalence in the spirit of Lucas (1987). We find that lowering the capital tax rate to zero leads to a substantial increase in the stock of capital equipments and in the relative quantity of skilled labor. The tax reform also creates a sizable increase in welfare. Yet, perhaps surprisingly, its effect on wage inequality is small.

The reduction in capital income taxes works through three channels to affect wage inequality. First, the reduction in capital taxes raises the stocks of capital equipments and, with equipmentskill complementarity, raises the relative marginal productivity of skilled workers as well. Second, related to the first, the reduction in capital taxes encourages skill accumulation and thereby lowers the skill premium, since the relative supply of skilled workers increases. Third, to keep the present

\footnotetext{
${ }^{3}$ More accurately, we are comparing two economies with the same $q$ series (and the same tax revenue), but with different factor-income tax rates.
} 
value of tax revenue unchanged, the reduction in capital taxes requires an increase in the labor income tax rate. Raising the labor income tax lowers the benefit of skill accumulation since skilled labor income is taxed at a higher rate; it also lowers the opportunity cost of time investment for skill accumulation. However, since goods investment for skill accumulation is not tax deductible, the higher labor tax reduces only part of the cost of skill accumulation. The total cost is thus reduced by less than the reduction in the benefit, and skill accumulation is discouraged (e.g., Trostel, 1993). As such, raising the labor income tax tends to increase the skill premium. Under calibrated parameters, the net effect of the capital-tax reduction on wage inequality is small.

In a second counterfactual experiment, we examine the effectiveness of two (revenue-neutral) policy changes that aim at reducing income inequality. One such policy is to raise the progressiveness of labor income taxes, and the other is to provide subsidies for human-capital investment. Increasing the progressiveness of labor taxes, although mechanically reduces the after-tax skill premium, is not effective in reducing wage inequality. Such a policy change discourages skill accumulation and thus increases the scarcity of skilled labor. Further, by lowering the average skill level, a more progressive labor taxation system can lead to a decline in average productivity and inflict a substantial welfare loss. In contrast, subsidizing skill accumulation can effectively reduce the skill premium through raising the relative quantity of skilled workers, and the policy change is welfare-improving.

In what follows, we present the model in Section 2, describe the calibration and solution methods in Section 3, discuss the main results in Section 4, present the counterfactual policy experiments in Section 5, and conclude in Section 6. In an appendix, we describe the data sources and computation methods.

\section{The Model}

We now present a general equilibrium model with vintage capital. The model features (i) investment-specific technological change, under which production of new capital equipments becomes increasingly efficient over time; (ii) equipment-skill complementarity, under which capital equipments are more complementary to skilled workers than to unskilled workers; and (iii) endogenous skill accumulations.

\subsection{The Economic Environment}

Time is discrete. The economy is populated by a large number of identical, infinitely lived households. The representative household is formed by a continuum of workers with a unit 
measure, who supply inelastically to the market one unit of time. In each period, a fraction of workers is skilled and the rest is unskilled. There exists a technology to transform unskilled labor into skilled labor, and such transformation requires both time and goods as inputs. The household derives utility from consumption of a final good, which is produced by a large number of firms using skilled labor, unskilled labor, capital equipments, and capital structures. The final good is also used for accumulations of physical capitals (equipments and structures) and human capital (skilled labor). A government collects revenues through proportional taxes on labor incomes and capital incomes, and rebates the proceeds to the representative household through lump-sum transfers. All agents have perfect foresight.

The representative household has a life-time discounted utility function

$$
\sum_{t=0}^{\infty} \beta^{t} \frac{c_{t}^{1-\sigma}}{1-\sigma}
$$

where $\beta \in(0,1)$ is a subjective discount factor, $c_{t}$ is consumption, and $\sigma>0$ is a relative risk aversion parameter.

The representative firm produces the final good, with the production function given by

$$
y_{t}=\tilde{k}_{s t}^{\theta}\left[\mu\left(z_{t} \tilde{u}_{t}\right)^{\nu}+(1-\mu)\left[\lambda \tilde{k}_{e t}^{\phi}+(1-\lambda)\left(z_{t} \tilde{s}_{t}\right)^{\phi}\right]^{\nu / \phi}\right]^{\frac{1-\theta}{\nu}},
$$

where $y_{t}$ denotes output, $\tilde{k}_{s t}$ denotes input of capital structures, $\tilde{k}_{e t}$ denotes input of capital equipments, $\tilde{u}_{t}$ denotes input of unskilled workers, $\tilde{s}_{t}$ denotes input of skilled workers, and $z_{t}$ denotes a (neutral) labor-augmenting technological change. The parameter $\theta \in(0,1)$ measures the elasticity of output with respect to capital structures, and the parameters $\phi$ and $\nu$ determine the elasticities of substitution between equipments and skilled labor and between the skill-equipment composite and unskilled labor, respectively. If $\phi<\nu<1$, then equipments are more complementary to skilled workers than to unskilled workers and the production technology features equipment-skill complementarity in the spirit of KORV (2000).

Physical capitals depreciate over time. Denote by $\delta_{s}$ and $\delta_{e}$ the depreciation rates for capital structures and equipments, respectively. Then, the laws of motion for these capital stocks are given by

$$
k_{s, t+1}=\left(1-\delta_{s}\right) k_{s t}+i_{s t},
$$

and

$$
k_{e, t+1}=\left(1-\delta_{e}\right) k_{e t}+i_{e t} q_{t}
$$

where we assume that new investments in capital structures $i_{s t}$ and in capital equipments $i_{e t}$ are both non-negative and $k_{s t}$ and $k_{e t}$ are the current stocks of such capitals. We interpret the term $q_{t}$ in (4), in the spirit of GHK (1997), as investment-specific technological change (ISTC) 
that enhances the productivity of newly formed capital equipments. One can also interpret $1 / q_{t}$ as the relative price of new capital equipments, which, according to the evidence provided by GHK (1997) and Cummins and Violante (2002), declined for most of the postwar period, and the decline has accelerated since the early 1980s. We will discuss more about $q_{t}$ in the calibration section. $^{4}$

We now describe the skill accumulation technology. The representative household consists of a continuum of workers with a unit measure, who supply inelastically one unit of time to the market. In each period $t$, a fraction $s_{t} \in(0,1)$ of workers is skilled and a fraction $u_{t}=1-s_{t}$ is unskilled. Denote $i_{h t} \geq 0$ the goods invested in skill accumulation and $e_{t} \in(0,1)$ the fraction of time of the unskilled workers used for skill transformation. The technology that transforms unskilled labor into skilled labor is given by

$$
s_{t+1}=(1-\eta) s_{t}+B\left[\left(\frac{i_{h t}}{z_{t}}\right)^{\alpha}\left[e_{t}\left(1-s_{t}\right)\right]^{1-\alpha}\right]^{\xi},
$$

where $\eta \in[0,1]$ measures the depreciation rate of existing skills and $\alpha, \xi$, and $B$ are parameters characterizing the production technology of new skills. In particular, $\alpha \in(0,1)$ measures the relative importance of goods input vs. time input, $\xi>0$ measures the returns to scale, and $B>0$ measures the efficiency of the skill transformation technology. We divide the goods input $i_{h t}$ by the level of the neutral technological change $z_{t}$ to keep the model consistent with balanced growth, under which the investment-specific technological change $q_{t}$ settles down at a constant level while the neutral technological change $z_{t}$ grows at a constant rate.

Some studies assume that effective time is the only input in human capital production (e.g., Heckman, 1976; Haley, 1976); some other studies assume that goods are the only input (e.g., Stokey, 1996). We follow Ben-Porath (1967) and Trostel (1993) and assume that skill accumulation requires both time and goods as inputs. This specification has important implications for studying the effects of taxation (as we do in the policy experiments below). ${ }^{5}$ As in Ben-Porath (1967) and Trostel (1993), we impose a unitary elasticity of substitution between goods and time invested in skill accumulation and we assume that the production of new skills exhibits decreasing returns to scale (i.e., $\xi<1$ ) to ensure an interior solution. Unlike Ben-Porath (1967) and Trostel (1993), our specification here implies that adding skilled workers also subtracts from the unskilled.

\footnotetext{
${ }^{4}$ Our model can be reinterpreted as a two-sector model, in which one sector produces consumption good and capital structures, and the other produces equipments. Each sector is subject to a sector-specific productivity shock. Then, under some conditions (e.g., perfect factor mobility and identical capital-labor ratio across sectors), such a two-sector model is isomorphic to the model used in our quantitative analysis. See also GHK (1997) for a similar result in an environment with Cobb-Douglas technologies.

${ }^{5}$ We are grateful to two anonymous referees for suggesting the inclusion of both time and goods in the skill transformation technology.
} 
The government collects tax revenues through proportional taxes on the household's capital income and labor income. In calculating the tax base for capital income taxes, there is a depreciation allowance. The government rebates tax revenues to the representative household through lump-sum transfers, so that

$$
\tau_{k}\left[\left(r_{s t}-\delta_{s}\right) k_{s t}+\left(r_{e t}-\delta_{e} / q_{t}\right) k_{e t}\right]+\tau_{l}\left(w_{s t} s_{t}+w_{u t} u_{t}\left(1-e_{t}\right)\right)=T_{t},
$$

where $\tau_{k}$ and $\tau_{l}$ are the tax rates on capital income and labor income, $r_{s t}$ and $r_{e t}$ are the rental rates on structures and equipments, $w_{s t}$ and $w_{u t}$ are the wage rates for skilled and unskilled workers, and $T_{t}$ is the lump-sum transfer.

\subsection{Competitive Equilibrium}

The representative household owns the physical capital (equipments and structures), which she rents to the representative firm at the competitive rental rates $r_{e t}$ for equipments and $r_{s t}$ for structures. A fraction $s_{t}$ of the members of the household supplies skilled labor to the firm at a competitive wage $w_{s t}$, a fraction $u_{t}\left(1-e_{t}\right)$ supplies unskilled labor to the firm at a competitive wage $w_{u t}$, and the remaining members of the household (of measure $u_{t} e_{t}$ ) invest their time for skill accumulation. The household takes the wage rates and the rental rates as given and chooses consumption $c_{t}$, investment in capital equipments $i_{e t}$, investment in capital structures $i_{s t}$, investment in human capital in terms of both goods $i_{h t}$ and foregone time $e_{t}$ to maximize the discounted utility (1) subject to a sequence of budget constraints

$$
\begin{aligned}
c_{t}+ & i_{e t}+i_{s t}+i_{h t} \leq\left(1-\tau_{l}\right)\left(w_{s t} s_{t}+w_{u t}\left(1-e_{t}\right)\left(1-s_{t}\right)\right) \\
& +\left(1-\tau_{k}\right)\left(r_{e t} k_{e t}+r_{s t} k_{s t}\right)+\tau_{k}\left(\delta_{e} k_{e t} / q_{t}+\delta_{s} k_{s t}\right)+T_{t}
\end{aligned}
$$

and the laws of motion (3), (4), and (5) for the physical capitals and the human capital, along with non-negativity constraints on $c, i_{e}, i_{s}, i_{h}$, and $e_{t}$.

The firm takes the wage rates and the rental rates as given, and chooses the quantities of inputs $\left\{\tilde{k}_{e t}, \tilde{k}_{s t}, \tilde{u}_{t}, \tilde{s}_{t}\right\}$ to solve a profit-maximizing problem

$$
\max \pi=y_{t}-w_{s t} \tilde{s_{t}}-w_{u t} \tilde{u}_{t}-r_{e t} \tilde{k}_{e t}-r_{s t} \tilde{k}_{s t}
$$

where the output $y_{t}$ is related to the inputs through the production function (2). As the production technology exhibits constant returns and the firm faces perfectly competitive markets, profit is zero in equilibrium.

A competitive equilibrium consists of a set of allocations $c_{t}, k_{e, t+1}, k_{s, t+1}, s_{t+1}, i_{e t}, i_{s t}, i_{h t}$, and $e_{t}$ for the representative household; a set of allocations $y_{t}, \tilde{k}_{e t}, \tilde{k}_{s t}, \tilde{u}_{t}$, and $\tilde{s}_{t}$ for the representative firm, a set of prices $r_{e t}, r_{s t}, w_{s t}$, and $w_{u t}$, and a profile of government policy $\left\{\tau_{k}, \tau_{l}, T\right\}$, such that 
1. Taking the prices and the policy as given, the household's allocations solve its utility maximizing problem.

2. Taking the prices and the policy as given, the firm's allocations solve its profit maximizing problem.

3. The government budget is balanced in each period.

4. Markets for the input factors and for the final good clear so that

$$
\tilde{k}_{e t}=k_{e t}, \quad \tilde{k}_{s t}=k_{s t}, \quad \tilde{s_{t}}=s_{t}, \quad \tilde{u}_{t}=u_{t}\left(1-e_{t}\right), \quad s_{t}+u_{t}=1,
$$

and

$$
y_{t}=c_{t}+i_{s t}+i_{e t}+i_{h t}
$$

\subsection{Equilibrium Dynamics}

We now characterize the equilibrium dynamics. The household's optimizing conditions can be reduced to three intertemporal Euler equations with respect to the three forms of capital: structures, equipments, and skills and one intratemporal decision with respect to the time allocated to skill accumulation.

The Euler equation for capital structures is given by

$$
c_{t}^{-\sigma}=\beta c_{t+1}^{-\sigma}\left[\left(1-\tau_{k}\right)\left(r_{s, t+1}-\delta_{s}\right)+1\right] .
$$

The left-hand side of the equation gives the marginal utility loss of foregoing one unit of consumption good to invest in capital structures in period $t$. The right-hand side of the equation gives the present value of marginal-utility gain in period $t+1$ from such investment, which equals the after-tax return on capital structures. In equilibrium, the utility gain equals the utility loss.

The Euler equation for capital equipments is given by

$$
\frac{c_{t}^{-\sigma}}{q_{t}}=\beta \frac{c_{t+1}^{-\sigma}}{q_{t+1}}\left[\left(1-\tau_{k}\right)\left(r_{e, t+1} q_{t+1}-\delta_{e}\right)+1\right] .
$$

This equation is similar to (10), except that the units need to be appropriately converted using the relative price $1 / q_{t}$ for new equipments.

To help derive and interpret the Euler equation for skill accumulation, we define a function

$$
f\left(i_{h t}, e_{t}, s_{t}\right)=B\left[\left(\frac{i_{h t}}{z_{t}}\right)^{\alpha}\left(e_{t}\left(1-s_{t}\right)\right)^{1-\alpha}\right]^{\xi},
$$

where $f_{i_{h t}}=\frac{\partial f}{\partial i_{h t}}>0, f_{e_{t}}=\frac{\partial f}{\partial e_{t}}>0$, and $f_{s t}=\frac{\partial f}{\partial s_{t}}<0$. The Euler equation for skill accumulation can then be written as

$$
\frac{c_{t}^{-\sigma}}{f_{i_{h t}}}=\beta c_{t+1}^{-\sigma}\left\{\frac{1-\eta+f_{s_{t+1}}}{f_{i_{h, t+1}}}+\left(1-\tau_{l}\right)\left[w_{s, t+1}-w_{u, t+1}\left(1-e_{t+1}\right)\right]\right\} .
$$


To understand this equation, note that each unit of consumption good invested in skill accumulation results in $f_{i_{h t}}$ units of new skills. In other words, $1 / f_{i_{h t}}$ measures the shadow price of newly formed skills. The left-hand side of (12) then represents the period- $t$ marginal utility loss from investing goods for producing an additional unit of skilled labor. The right-hand side represents the present value of the marginal utility gain from having this additional unit of skilled labor. In particular, the utility gain consists of two components: (i) the remaining value of the skills after taking into account of skill depreciation $(\eta>0)$ and the reduction in the number of unskilled workers available to be transformed into skilled workers $\left(f_{s}<0\right)$, and (ii) the marginal increase in the after-tax wage income for adding a unit of skilled labor (and thereby subtracting a unit from the unskilled). In equilibrium, the utility gain and loss are equal, so that the household remains indifferent at the margin of the skill accumulation decisions.

The optimizing decision on the time invested for skill accumulation is given by

$$
f_{e t}=f_{i_{h t}}\left(1-\tau_{l}\right) w_{u t}\left(1-s_{t}\right)
$$

This equilibrium relation reflects that, at the margin, the household should remain indifferent between investing time versus investing goods in skill accumulation. Investing a marginal unit of time produces $f_{\text {et }}$ units of skilled labor; alternatively, investing a marginal unit of consumption goods produces $f_{i_{h t}}$ units of skilled labor. The time investment bears an opportunity cost equal to the after-tax labor income of the unskilled workers. In equilibrium, the household is indifferent between these two alternative means of producing an additional unit of skilled labor.

The firm's optimizing decisions equate the prices of input factors to their marginal products. To simplify expressions, we define

$$
\tilde{y}_{t}=\left[\mu\left(z_{t} u_{t}\left(1-e_{t}\right)\right)^{\nu}+(1-\mu)\left(\lambda k_{e t}^{\phi}+(1-\lambda)\left(z_{t} s_{t}\right)^{\phi}\right)^{\nu / \phi}\right]^{1 / \nu},
$$

so that the production function can be written as $y_{t}=k_{s t}^{\theta} \tilde{y}_{t}^{1-\theta}$. The factor prices are given by

$$
\begin{aligned}
r_{s t} & =\theta\left(\frac{\tilde{y}_{t}}{k_{s t}}\right)^{1-\theta} \\
r_{e} & =\lambda(1-\theta)(1-\mu) k_{s t}^{\theta} \tilde{y}_{t}^{1-\theta-\nu}\left[\lambda k_{e t}^{\phi}+(1-\lambda)\left(z_{t} s_{t}\right)^{\phi}\right]^{\frac{\nu}{\phi}-1} k_{e t}^{\phi-1} \\
w_{s} & =(1-\lambda)(1-\theta)(1-\mu) k_{s t}^{\theta} \tilde{y}_{t}^{1-\theta-\nu}\left[\lambda k_{e t}^{\phi}+(1-\lambda)\left(z_{t} s_{t}\right)^{\phi}\right]^{\frac{\nu}{\phi}-1} z_{t}^{\phi} s_{t}^{\phi-1} \\
w_{u} & =(1-\theta) \mu k_{s t}^{\theta} \tilde{y}_{t}^{1-\theta-\nu}\left(u_{t}\left(1-e_{t}\right)\right)^{\nu-1} z_{t}^{\nu} .
\end{aligned}
$$

Denote by $\pi_{s t}=\frac{w_{s t}}{w_{u t}}$ the skill premium. From equations (17) and (18), the skill premium is given by

$$
\pi_{s t}=\frac{(1-\mu)(1-\lambda)}{\mu}\left[\lambda\left(\frac{k_{e t}}{z_{t} s_{t}}\right)^{\phi}+(1-\lambda)\right]^{\frac{\nu-\phi}{\phi}}\left[\frac{u_{t}\left(1-e_{t}\right)}{s_{t}}\right]^{1-\nu} z_{t}^{\phi-\nu} .
$$


If $1>\nu>\phi$, then capital equipments are more complementary to skilled labor than to unskilled labor. With such equipment-skill complementarity, we have

$$
\frac{\partial \pi_{s}}{\partial\left(k_{e} / s\right)}>0, \quad \frac{\partial \pi_{s}}{\partial[s /(u(1-e))]}<0 .
$$

In other words, the skill premium increases with the equipment-skill ratio (the equipment-skill complementarity effect), and decreases with the skilled-unskilled ratio (the relative quantity effect).

To summarize, we have 12 equilibrium conditions, including the three Euler equations (10)(12), the intratemporal decision on the time input for skill accumulation (13), the three capital accumulation equations (3)-(5), the four factor-price equations (15)-(18), and the aggregate resource constraint (9). These equilibrium conditions jointly determine the equilibrium values of 12 variables $\left\{c_{t}, i_{s t}, i_{e t}, i_{h t}, e_{t}, k_{e, t+1}, k_{s, t+1}, s_{t+1}, r_{e t}, r_{s t}, w_{s t}, w_{u t}\right\}_{t=0}^{\infty}$.

\subsection{Balanced Growth}

Since investment-specific technological change $q_{t}$ is capital augmenting rather than labor augmenting, the model economy with a CES production function as the one in (2) would attain balanced growth only if there is no secular growth in $q_{t}$ (e.g., Hornstein and Krusell, 2003). Of course, if the production function is Cobb-Douglas, as in GHK (1997), then balanced growth can be attained even if $q_{t}$ grows at a constant rate. More formally, we have the following proposition. Proposition 1: The balanced growth path (BGP) in this economy cannot be achieved unless there is no secular growth in the investment-specific technological change or the elasticities of substitution between input factors are unitary.

Proof: By contradiction. Without loss of generality, suppose that the neutral technological change $z_{t}$ stays constant. Suppose there were a BGP with a positive growth in the investmentspecific technological change $q$. Along the BGP, the growth rates of $y, k_{e}$, and $k_{s}$, and the levels of $s$ and $u$ are all constant. Let $\gamma_{x}$ denote the growth rate of a variable $x$. Then, from the resource constraint and the laws of motion of physical capital stocks, we have $\gamma_{y}=\gamma_{k_{s}}$ and $\gamma_{k_{e}}=\gamma_{y}+\gamma_{q}$. The production function $y_{t}=k_{s t}^{\theta} \tilde{y}_{t}^{1-\theta}$ implies that $\gamma_{y}=\gamma_{\tilde{y}}$, which leads to a contradiction because $\gamma_{\tilde{y}}$ is in general not a constant, as $k_{e}$ grows at a constant rate, while the levels of $s, e$, and $u$ remain constant on a BGP.

In the case with unitary elasticities of substitution between input factors (i.e., Cobb-Douglas production function), there exists a BGP, as shown by GHK (1997).

We do not consider the case with a Cobb-Douglas production function because it is inconsistent with the evidence of equipment-skill complementarity; we do not restrict $q_{t}$ to be constant 
because we would like to examine the role of investment-specific technological change (i.e., a timevarying $q_{t}$ ) in accounting for the observed dynamics in wage inequality and skill accumulation. To isolate the role $q_{t}$, we shut off the neutral technological change by assuming that $z_{t}=1$ for all $t$. In computing the equilibrium dynamics, we interpret the growth in the investment-specific technological change as a transition from some initial steady state to a new steady state, and we focus on computing the transition dynamics of wage inequality and the relative quantity of skilled labor in the economy where agents have perfect foresight about the future time path of $q_{t} \cdot{ }^{6}$

\section{The Calibration and Solution Methods}

We now describe our approach to calibrating the parameters to be used in our computation of the transition dynamics.

The parameters to be calibrated include $\beta$, the subjective discount factor; $\sigma$, the relative riskaversion parameter; $\theta, \lambda$, and $\mu$, which determine the income shares of capital structures, capital equipments, and unskilled labor; $\phi$ and $\nu$, which determine the elasticities of substitution between equipments and skilled labor and between the equipment-skill composite and unskilled labor; $\delta_{s}$, $\delta_{e}$, and $\eta$, the depreciation rates of structures, equipments, and skills; $B, \alpha$, and $\xi$, parameters in the skill transformation technology; and $\tau_{k}$ and $\tau_{l}$, the tax rates on capital and labor incomes. The calibrated parameter values are summarized in Table 1 .

We set $\sigma=1.5$, a standard value used in the literature. We follow GHK (1997) and set $\theta=0.13, \delta_{s}=0.056$, and $\delta_{e}=0.124$. We set $\phi=-0.495$ so that the elasticity of substitution between capital equipments and skilled labor is about 0.67 , which is the value estimated by KORV (2000). Based on the estimation by Duffy et al. (2004), we set $\nu=0.79$ as a benchmark. Since the empirical literature provides a wide range of estimates for $\nu$ (see Hamermesh, 1993), we also consider some other values of $\nu$ in our policy experiments, including the value of $\nu=$ 0.401 estimated by KORV (2000). Heckman's (1976) estimates suggest that the returns to scale parameter $\xi$ varies in the range between 0.51 and 0.81 . We set $\xi=0.7$ as a benchmark value, which lies within the range of Heckman's estimates and is also the value used by Stokey (1996).

\footnotetext{
${ }^{6}$ Since our focus is to examine to what extent the increases in the skill premium and the relative quantity of skilled labor can be accounted for by the observed increase in $q_{t}$ (and its acceleration since the early 1980s), assuming perfect foresight does not seem to lose much generality. Ideally, the model should be solved under rational expectations with a stochastic process for $q_{t}$. A difficulty with this approach is that, as we show in Proposition 1 , a balanced growth path does not exist in our model with a CES production function if $q_{t}$ contains a trend. Thus, the traditional solution methods involving log-linearizing around a balanced growth path do not apply. Developing computational techniques to solve nonlinear rational-expectations model without balanced growth remains an important challenge for future research. In our view, this issue is important enough to deserve a separate investigation.
} 
In our policy experiments, we also consider some other values of $\xi$ in the range between 0.5 and 0.8. According to Heckman's (1976) estimates, the rate of human capital depreciation ranges from 0.04 to 0.09. We set $\eta=0.08$, which is also the value used by Stokey (1996). We set the average capital income tax rate to $\tau_{k}=0.397$, a value used by Domeji and Heathcote (2004), and the average labor income tax rate to $\tau_{l}=0.277$, following the work by McGrattan (1994) and Mendoza et al. (1994).

This leaves five parameters to be calibrated, including $B, \alpha, \beta, \lambda$, and $\mu$. We assign values to these parameters so that the initial steady state in the model matches five moment conditions observed in the data in $1949 .{ }^{7}$ These five moment conditions are as follows:

1. The college wage premium (i.e., the average annual wage of college graduates relative to that of high-school graduates) is 1.456 in 1949 (Census data).

2. The expenditure in skill accumulation as a fraction of GDP is about 1.8\% in 1949 (Data source: National Center for Educational Statistics, DES 2003).

3. The average capital-output ratio is 2.659 for the period between 1947 and 1949 (NIPA data).

4. The average income share of capital stock is 0.267 for the period between 1947 and 1949 (NIPA data).

5. The ratio of skilled labor (i.e., college graduates) to unskilled labor (i.e., high-school graduates) is 0.288 in 1949 (Census data).

Table 1 reports the values of these five parameters required to match the five initial moment conditions. There we have $B=0.349, \alpha=0.60, \beta=0.988, \lambda=0.491$, and $\mu=0.423$.

To measure the investment-specific technological change series $q_{t}$, we rely on the study by Cummins and Violante (2002), who construct a quality-adjusted time series of the price index for 24 types of equipments and softwares during the period from 1947 to 2000, in the spirit of an earlier study by Gordon (1990). Upon obtaining the price index for equipments and softwares, we divide it by the price index of consumer non-durables and services reported in the National Income and Product Accounts (NIPA) to obtain a (quality-adjusted) relative price of new equipments and softwares. The investment-specific technological change (i.e., the $q_{t}$ series) is then the inverse of this relative price. The resulting $q_{t}$ series is plotted in Figure 3. The figure shows that $q_{t}$ has been increasing for most of the postwar period, and its growth has accelerated since the early 1980s.

\footnotetext{
${ }^{7}$ We choose 1949 as the initial steady state, since our $q_{t}$ series constructed based on Cummins and Violante (2002) appears fairly stable between 1947 and 1949.
} 
The average growth rate of $q_{t}$ was $3.45 \%$ for the period $1950-1980$ and increased to $5.83 \%$ for the period 1981-2000.

As we have discussed earlier, we interpret the growth in the ISTC during the period from 1949 to 2000 as part of a transition from some initial steady state to a new steady state, where the ISTC becomes stable. To compute the transition dynamics, we assume that the growth rate of the ISTC slows down linearly starting in year 2001, and reaches zero in 2050. To ensure convergence to the final steady state, we further extend the (hypothetical) sample period for the ISTC series to year 2108. This way, we obtain a time series for $q_{t}$ with a length of 160 years, consisting of 52 years of actual observations between 1949 and 2000 taken from Cummins and Violante (2002) and 108 additional years for $q_{t}$ to settle down at a new steady state. ${ }^{8}$

To compute the transition dynamics in the model, we first solve for the initial steady state and the final steady state given the values of the $q_{t}$ series in the initial and the final steady states. Table 2 summarizes the solutions for some key variables in the initial steady state (with $q_{1}=1$ ) and compares these solutions with the corresponding moments in U.S. data (i.e., the values in 1949). The first five moment conditions in Table 2 match the data by construction. The model does fairly well on the other two dimensions. The average consumption-output ratio in the model is about $77 \%$, which is close to the observed value of $81 \%$; the ratio of capital equipments to capital structures in the model is 0.56 , which is not far from that in the data $(0.64) .{ }^{9}$

Upon obtaining the solutions for the initial and the final steady states in the model, we compute the transition dynamics using a non-linear solution methods in the spirit of Conesa and Krueger (1999), Chen, İmrohoroğlu and İmrohoroğlu (2006), and He (2006). The details of the solution algorithm are described in Appendix B.

\section{Dynamic Implications of the Model}

We now describe the equilibrium dynamics of wage inequality and the relative quantity of skilled labor driven solely by the measured investment-specific technological change. We compare the model's predictions with the observations in the U.S. data.

\footnotetext{
${ }^{8}$ Our quantitative results are not sensitive to alternative assumptions about what happens to the ISTC after 2001. For instance, when we assume that the ISTC stops growing in 2010 (instead of 2050), we obtain almost identical results.

${ }^{9}$ The equipment-structure ratio in the data is the average value for the period 1963-1992 taken from KORV (2000). Ideally, we should compare the model's initial steady state value with the value in 1949 in the data. Unfortunately, quality-adjusted data of capital equipments in 1949 are not available. As the relative productivity of equipments has been rising since 1949, it is reasonable to believe that the equipment-structure ratio in 1949 should be lower than the average value for 1963-1992, and therefore be closer to our model's prediction.
} 
Figure 4 plots the skill premium (in log units) generated from the model and that in the data for the period between 1963 and 2000. The model does well in accounting for the substantial rise in wage inequality since the early 1980s. In particular, wage inequality measured by the relative wages of skilled workers in the U.S. economy has increased by about 19\% between 1984 and 2000 . The model predicts an increase of $14 \%$. The model fails to capture the earlier episodes in the evolution of wage inequality, especially that in the 1970s. This is perhaps not surprising, since other factors such as demographic changes associated with the baby boom generation, which we do not model here, might also be driving the observed changes in wage inequality in the 1970s (e.g., Katz and Murphy, 1992; He, 2006). ${ }^{10}$

Figure 5 plots the dynamics of the relative quantity of skilled labor predicted by the model and that observed in the data. The model's prediction tracks the data surprisingly well for the entire sample period from 1963 to 1996. The result here suggests that the observed secular increase in the relative quantity of skilled labor can be mostly accounted for by investment-specific technological change.

Our model contains a simple mechanism that propagates the investment-specific technological change to generate the observed patterns in skill accumulation and wage inequality. As $q_{t}$ grows over time, the relative price of capital equipments falls, which encourages the household to invest in new equipments so that the stock of capital equipments grows over time. Because of equipmentskill complementarity, the increase in the stock of equipments raises the marginal productivity of skilled workers and lowers that of unskilled workers and thereby driving up the skill premium. As such, the household finds it optimal to invest more in human capital and the skilled-unskilled ratio rises over time. Although the increase in the skilled-unskilled ratio dampens the rise in the skill premium, the equipment-skill complementarity effect dominates. Under calibrated parameters, our model predicts that both the skill premium and the skilled-unskilled ratio rise over time, as in the data. ${ }^{11}$

\footnotetext{
${ }^{10} \mathrm{~A}$ main discrepancy between the model's predictions and the data seems to be the two spikes in the skill premium predicted (incorrectly) by the model. The timing of these spikes appears to coincide with those in the $q_{t}$ series (see Figure 3). It is not clear what drives the spikes in the $q_{t}$ series. The timing suggests that oil price shocks in the 1970s may have been a contributing factor. High oil prices render some capital equipments obsolete, leading to higher equipment investment and a higher equipment price. As the effects of oil shocks are expected to dissipate, the price of equipments is expected to fall, and thus productivity of the equipment sector (i.e., $q_{t}$ ) is expected to rise after the oil shocks.

${ }^{11}$ In an unreported experiment, we examine the quantitative importance of endogenous skill accumulation for capturing the trend in the skill premium. For this purpose, we consider an extreme case with $\xi=0$, so that skill accumulation is prohibitively costly and the equilibrium relative quantity of skilled labor is constant. In this case, the model substantially overstates the trend in the skill premium: the skill premium rises by about $35 \%$ in the
} 
The propagation mechanism in the model implies that, as production of new equipments becomes more efficient over time, the average labor productivity measured by output per hour grows as well. GHK (1997) find that investment-specific technological change accounts for about $58 \%$ of the average annual growth rate in output per hour in the United States for the period 1954-1990. Our model generalizes the model in GHK (1997) by incorporating equipment-skill complementarity and endogenous human-capital accumulation. The presence of these new elements, however, does not alter the main quantitative results obtained by GHK (1997). Our model driven solely by investment-specific technological change predicts that the average growth rate of output per hour is $0.64 \%$ during the period $1954-1990$, compared to $1.24 \%$ in the data. In other words, investment-specific technological change accounts for about $52 \%$ of the average growth in output per hour observed in the U.S. economy.

Our model has also interesting implications for measured total factor productivity (TFP). Since we assume a constant neutral technology in our model and the ISTC is the only source of equilibrium dynamics, changes in output reflects changes in measured input factors only. We can thus measure TFP by the difference between actual GDP in the data and output in the model. The TFP series so measured displays a productivity slowdown since the early 1980s: the average annual growth rate of TFP was 2.38\% for 1950-1979 and became lower at 1.09\% for 1980-2000. The slowdown in TFP growth coincides with the acceleration in the ISTC growth since the early 1980s, and it is a simple consequence of growth accounting: in the latter sample period, faster growth in the ISTC leads to faster growth in input factors and thus a larger fraction of output growth being accounted for by input growth.

To summarize, our results suggest that the ISTC can be an important source of growth in average labor productivity and the acceleration in the ISTC growth since the early 1980s may have contributed to the observed productivity slowdown. More importantly, our model accounts for much of the steady growth in the relative quantity of skilled labor in the postwar U.S. economy, and it does well in replicating the substantial rise in wage inequality since the early 1980s.

\section{Tax Reforms and Efficiency-Inequality Trade-offs}

The dynamic behavior of wage inequality in our model is driven by two competing forces between a "relative quantity effect" and an "equipment-skill complementarity effect." Thus, not only investment-specific technological change, but other factors that affect capital accumulation might also affect wage inequality. In this section, we first illustrate this possibility by considering a model for the period 1984-2000, but only $19 \%$ in the data for the same period. Thus, we need both equipment-skill complementarity and endogenous skill accumulation to match the time path of the skill premium. 
counterfactual capital-income tax reform that encourages capital accumulation. We then examine the effectiveness of some hypothetical tax policies that aim at reducing income inequality. ${ }^{12}$

\subsection{Counterfactual Experiment I: Eliminating Capital Income Taxes}

We now examine the quantitative effects of eliminating capital income taxes on wage inequality and skill accumulation. When we eliminate capital income taxes, we adjust labor income taxes so that the present value of the tax revenues during the entire transition period remains the same as in the benchmark economy. Since a zero capital income tax is consistent with the Ramsey optimal tax policy (e.g., Chamley, 1986), we also calculate the welfare gains from the tax reform.

In our quantitative experiment, we compare wage inequality and welfare in two economies, both driven by the same investment-specific technological change (i.e., our $q_{t}$ series). The two economies are identical except for their tax policies. One economy is our benchmark model, which has positive tax rates on both capital and labor, with $\tau_{k}=39.7 \%$ and $\tau_{l}=27.7 \%$. The other economy has a zero tax on capital, but a higher tax on labor so that the present value of the total tax revenue during the transition period remains the same as in our benchmark economy. The required labor income tax rate in this latter economy is $\tilde{\tau}_{l}=32.83 \%{ }^{13}$

Figure 6 plots the wage inequality for the two economies with different tax policies. Apparently, eliminating capital income taxes raises wage inequality modestly. For the period of our interest, 1949-2000, wage inequality in the economy with a zero capital income tax is on average $3.3 \%$ higher than that in the benchmark economy. The effects of the tax reform on wage inequality also vary with time. Beginning in the early 1980s, as the growth in the investment-specific technological change accelerates, the tax reform has a larger impact on wage inequality than in the earlier periods.

As wage inequality measured by the skill premium depends on both the equipment-skill ratio and the skilled-unskilled ratio (see equation (19)), it is instructive to examine the effects of the capital tax reform on these two determinants. Figure 7 plots the effects of eliminating capital income taxes on the relative quantity of skilled labor (the top panel) and on the equipment-skill ratio (the bottom panel). The figure reveals that the reduction in capital taxes raises both the relative quantity of skilled labor and the equipment-skill ratio. The gap between the skilledunskilled ratio before and after the capital tax reduction appears to become larger over time. The

\footnotetext{
${ }^{12}$ For some recent quantitative studies about the effects of changes in tax policies on wage inequality and welfare, see, for example, Blankenau (1999) and Blankenau and Ingram (2002). A key difference between these studies and ours is that we emphasize the role of investment-specific technological change in driving wage inequality.

${ }^{13}$ In calculating the present value, the discount factor that we use is the "state price" $D_{t, t+j}=\beta^{j}\left(c_{t+j} / c_{t}\right)^{-\sigma}$. Since we assume a complete asset market, the state price is unique.
} 
gap between the equipment-skill ratio displays substantial time variations, and becomes larger in the post-1980 period.

These results suggest that there are interesting interactions between the capital income tax reform and investment-specific technological change in shaping the dynamics of wage inequality and skill accumulation. As production of new equipments becomes more efficient over time, eliminating capital income taxes would create further incentive for capital accumulation, which, through equipment-skill complementarity, leads to greater wage inequality and more skill accumulation. The overall effects of the tax reform on skill accumulation and the equipment-skill ratio seem to be large, with an average increase of about $24 \%$ in the skilled-unskilled ratio and about $20 \%$ in the equipment-skill ratio relative to the pre-reform levels during the period between 1949 and 2000. Since the skilled-unskilled ratio and the equipment-skill ratio drive the skill premium to opposite directions, the overall effect of the tax reform on wage inequality is modest at about $3.3 \%$ relative to the benchmark economy. ${ }^{14}$

Why does eliminating capital income taxes lead to a modest increase in wage inequality and a substantial rise in the relative quantity of skilled labor? As we have alluded to in the introduction, the elimination of capital income taxes can affect wage inequality and skill formation through three channels. First, eliminating capital taxes encourages the household to invest in physical capitals which, through the equipment-skill complementarity, raises the relative marginal productivity of skilled workers and hence the skill premium. Second, related to the first, the expectation of a higher future skill premium provides an incentive for the household to invest in skill accumulation, which raises the skilled-unskilled ratio and reduces the skill premium. Third, to keep the present value of tax revenue unchanged, the reduction in capital taxes requires an increase in the labor income tax rate. Raising the labor income tax lowers the benefit of skill accumulation since skilled labor income is taxed at a higher rate; it also lowers the opportunity cost of time invested in human capital. However, since goods invested in human capital are not tax deductible, the higher labor tax reduces only part of the cost of human capital investment. The reduction in total cost is thus less than the reduction in the benefit, and skill accumulation is discouraged (e.g., Trostel, 1993). As such, raising the labor income tax tends to increase the skill premium. Under calibrated parameters, the capital tax reduction leads to a modest increase in wage inequality and a substantial rise in the relative quantity of skilled labor.

\footnotetext{
${ }^{14}$ We have also computed the average differences between wage inequality and skill accumulation for the entire transition period (with 160 years). The average increase in wage inequality associated with the elimination of capital taxes in this extended sample becomes $1.49 \%$ of its pre-reform level, and the average effect on the relative quantity of skilled labor becomes $14.29 \%$.
} 
Since a zero capital income tax rate is consistent with Ramsey optimal fiscal policy (e.g., Chamley, 1986), one should expect the tax reform to increase social welfare in our model. Indeed, it does. We measure welfare gains by a consumption equivalence in the spirit of Lucas (1987). In particular, we define welfare gains from the reduction of capital income taxes as the permanent percentage increase in consumption that is required for the representative household to remain indifferent between living in two economies: the benchmark economy with positive capital and labor taxes, and an alternative economy with no capital income taxes but a higher labor income tax rate. For the period between 1949 and 2000, we find that the welfare gain from eliminating capital income taxes is equivalent to a $1.32 \%$ permanent increase in consumption. The size of the welfare gains here is quite close to that obtained by Domeji and Heathcote (2004) in a representative-agent version of their model $(1.5 \%)$, and is sizable relative to the welfare cost of business cycle fluctuations calculated, for example, by Lucas (1987).

Eliminating capital income taxes creates a sizable welfare gain for two reasons. First, it removes intertemporal distortions in capital accumulation. Second, and more important, it raises average productivity through encouraging skill accumulation. The first channel is familiar in the Ramsey tax literature, but the second is new and is unique to our model with equipment-skill complementarity and with endogenous skill accumulation.

To examine the robustness of these results, we consider variations in two key parameters: $\nu$ and $\xi$. The parameter $\nu$ determines the importance of equipment-skill complementarity (for a given value of $\phi$ ), through which investment-specific technological change and tax policies can affect wage inequality. The parameter $\xi$ measures the returns to scale of the skill transformation technology: a lower value of $\xi$ means that transforming unskilled labor into skilled labor is more costly and thus the effects of $q_{t}$ or tax policies on skill accumulation is more muted. As we have discussed in the calibration section, the empirical literature provides a wide range of estimates for $\nu$ and $\xi$. Thus, it is important to know to what extent our results depend on the values of these parameters.

We first examine the quantitative effects of eliminating capital income taxes on wage inequality and skill accumulation for alternative values of $\nu$, while holding $\xi$ at its benchmark value (0.7). In addition to our benchmark calibration with $\nu=0.79$, we consider two alternative values of $\nu$ used in the literature. One is estimated by KORV (2000), which gives $\nu=0.401$; the other is estimated by Denny and Fuss (1977), which gives $\nu=0.65$. We do the same counterfactual experiments of tax reforms using these alternative values of $\nu$. The results are reported in Table 3 (Panel A). The table shows that, as $\nu$ becomes smaller, the effects of eliminating capital income taxes on wage inequality, the skill-unskilled ratio, the equipment-skilled ratio, and welfare become 
more muted. A smaller value of $\nu$ implies weaker equipment-skill complementarity, so that the rise in equipment investment induced by the tax reform is associated with a smaller increase in the skill premium and a weaker incentive for skill accumulation. But for all the values of $\nu$ that we have considered here, the tax reform leads to a sizable welfare gain and a modest rise in wage inequality.

We next examine the effects of eliminating capital income taxes for alternative values of $\xi$, while holding $\nu$ at its benchmark value (0.79). Table 3 (Panel B) displays the results. As the value of $\xi$ becomes smaller (from 0.8 to 0.5 ), transforming unskilled labor into skilled labor becomes more

costly. As such, the increase in equipment investment induced by the tax reform leads to a smaller increase in the skilled-unskilled ratio (from about $29 \%$ to about 14\%) and a slightly larger increase in the equipment-skill ratio (from about $20 \%$ to about $21 \%$ ). As the rise in the skilled-unskilled ratio is dampened (while the rise in the equipment-skill ratio remains roughly unchanged), the rise in the skill premium is magnified (from $2.28 \%$ to $5.26 \%$ ). As skill accumulation becomes more costly, the welfare gain from eliminating capital income taxes becomes smaller (from 1.44\% to $1.20 \%$ ). But even for the lowest value of $\xi$ that we consider here, the rise in wage inequality remains modest (at about 5\% compared to the benchmark economy) and the welfare gain remains sizable (at above $1 \%$ of consumption equivalence).

To summarize, eliminating capital income taxes can have large effects on skill accumulation and can lead to sizable welfare gains, but it has modest effects on wage inequality. This result is robust to alternative values of key parameters. Our experiment thus suggests that a capital tax reform such as the one in 1986 is unlikely to be a good candidate for explaining the substantial rise in wage inequality since the 1980s.

\subsection{Counterfactual Experiment II: Policies Designed to Reduce Inequality}

We now examine the effectiveness of two tax policies, both designed to reduce income inequality. One such policy is to increase the progressiveness of labor income taxes by imposing a higher tax rate on skilled labor income (denoted by $\tau_{s}$ ) than on unskilled labor income (denoted by $\left.\tau_{u}\right)$. When we change the labor income taxes, we adjust the capital income taxes so that the present value of the tax revenues during the entire transition period remains the same as in the benchmark economy. The other policy is to provide subsidies for human capital accumulation, while adjusting the labor income tax rate (common to both types of labors) to keep the policy change revenue neutral.

Table 4 reports the effects of increasing the progressiveness of labor income taxes on wage inequality, skill accumulation, and welfare. The table shows that, when the uniform labor tax in 
the benchmark model with $\tau_{s}=\tau_{u}=27.7 \%$ is replaced by a modestly progressive tax system with $\tau_{s}=30.22 \%$ and $\tau_{u}=25.18 \%$ (so that $\tau_{s} / \tau_{u}=1.2$ and $\left(\tau_{s}+\tau_{u}\right) / 2=27.7 \%$ ), the after-tax skill premium falls by $2.25 \%$; but the before-tax skill premium, which captures the general equilibrium effect, rises by $4.81 \%$. Following such a policy change, the skilled-unskilled ratio falls by $18.32 \%$ and the welfare is reduced by $1.24 \%$ of consumption equivalence. When the progressiveness further increases, the after-tax skill premium falls by more, but no more than $10.4 \%$ even when the tax rate for skilled labor goes up to twice that for the unskilled. Meanwhile, when $\tau_{s} / \tau_{u}$ rises from 1 to 1.6 (i.e., $\tau_{s}=34.09 \%$ and $\tau_{u}=21.31 \%$ ) and then to 2.0 (i.e., $\tau_{s}=36.93 \%$ and $\tau_{u}=18.47 \%$ ), the before-tax skill premium rises from $0 \%$ to $12 \%$ and then to $16 \%$; the skilled-unskilled ratio falls from $0 \%$ to $-44 \%$ and then to $-63 \%$; and the welfare loss rises from $0 \%$ to $4.3 \%$ and then to $8.9 \%$. These results suggest that raising the progressiveness of labor income taxes, although mechanically redistributes income, is not effective in reducing wage inequality. Such a policy discourages skill accumulation and can lead to large welfare losses.

Progressive labor income taxes affect the skill premium and skill accumulation through three channels. First, raising the progressiveness reduces the benefit of skill accumulation since the labor income of skilled workers is taxed at a higher rate. It also raises the opportunity cost of time invested for skill accumulation since the after-tax wage income for unskilled workers goes up. Thus, raising the progressiveness discourages skill accumulation, which drives up the skill premium. Second, holding the capital income tax constant, as the quantity of skilled labor falls through the first channel, the equipment-skill ratio should rise, which, through the equipment-skill complementarity effect, tends to drive up the skill premium as well. Third, to keep the policy change revenue neutral requires raising the capital income tax rate, which discourages physical capital accumulation, so that the equipment-skill ratio and therefore the skill premium may fall. As Table 4 shows, the equipment-skill ratio rises slightly for modestly progressive labor taxes (as the reduction in skilled labor dominates) but falls slightly for large progressiveness (when the reduction in the stock of capital equipments dominates). Our results reveal that the first channel dominates, so that progressive labor taxes lead to large declines in the relative quantity of skilled labor, large losses in welfare, but not much reduction in (after-tax) wage inequality.

We now consider an alternative policy that, instead of making labor income taxes more progressive, provides subsidies to human capital investment. Denote the subsidy rate by $\tau_{h}$. Under the subsidy policy, the household's budget constraint (7) and the government budget constraint (6) should be modified accordingly. In particular, in the household's budget constraint, the term $i_{h}$ should be replaced by $\left(1-\tau_{h}\right) i_{h}$; and in the government budget constraint, the expenditure associated with the subsidy in the amount of $\tau_{h} i_{h}$ should be subtracted from the tax revenues. 
To maintain the present value of tax revenues the same as in the benchmark economy without subsidies, we adjust the labor income tax rate $\tau_{l}$ when we increase the value of $\tau_{h}$.

Table 5 reports the effects of subsidizing human capital accumulation. The table shows that, as the subsidy rate increases, the skill premium and the equipment-skill ratio both decline, and the relative quantity of skilled labor and welfare both increase. Even a modest increase in the subsidy rate, say from 0 (the benchmark economy) to $8 \%$, can result in a sizable reduction in the skill premium (1.39\%), a significant increase in the relative quantity of skilled labor (5.47\%), and a non-trivial welfare gain $(0.30 \%)$. Subsidizing human capital investment provides incentive for skill accumulation, and thereby raises the skilled-unskilled ratio and lowers the equipment-skill ratio, both of which tend to reduce the skill premium. By raising the relative quantity of skilled labor, a subsidy leads to more labor-tax revenue for any given labor income tax rate; as such, to keep revenue neutral, the required labor tax goes down. Thus, a subsidy to human capital counteracts some of the distortions associated with labor taxes and improves welfare. This result suggests that subsidizing human capital accumulation does not seem to involve a trade-off between equity and efficiency.

\section{Conclusion}

Understanding the driving forces of wage inequality is of great interest to both academic researchers and policy makers. In the literature, many potential mechanisms are proposed for explaining the qualitative changes in wage inequality. Yet, quantitative studies of the relative importance of these mechanisms are scarce. In the current paper, we have examined the quantitative importance of the investment-specific technological change in explaining the dynamics of wage inequality and skill accumulation in a general equilibrium model. We find that, working through equipment-skill complementarity and endogenous skill accumulation, investment-specific technological change is able to account for much of the observed dynamics in the relative quantity of skilled labor in the postwar U.S. economy, and the model does fairly well in replicating the substantial rise in wage inequality since the early 1980s. In our counterfactual experiments, we find that a revenue-neutral elimination of capital income taxes leads to a modest increase in wage inequality and a sizable welfare gain. We also find that a revenue-neutral increase in the progressiveness of labor income taxes is not effective in reducing income inequality and, since it discourages skill accumulation, can potentially lead to large declines in average productivity and welfare. In contrast, a policy that provides direct subsidies for human capital accumulation tends to raise the skilled-unskilled ratio, lower the skill premium, and improve welfare. 
We focus on the role of investment-specific technological change in explaining the dynamic evolution of wage inequality and skill accumulation mainly because such technological change can be explicitly measured, thanks to the empirical work by Gordon (1990), GHK (1997), KORV (2000), and Cummins and Violante (2002). Such technological change turns out to be a quantitatively important mechanism in explaining wage inequality, but we do not claim it is the only mechanism. Future work should incorporate other mechanisms such as demographic changes (that affect human capital accumulation) or institutional reforms (that affect the relative returns to education), and evaluate the quantitative importance of these alternative mechanisms in explaining the dynamics of wage inequality, especially for the period before 1980 .

Another direction to extend our study is to introduce consumer heterogeneity. Since our focus is on income inequality, we have taken a representative-agent approach, which implicitly assumes perfect risk-sharing between households. As such, there is no consumption inequality in our model. Incorporating consumer heterogeneity can be potentially important for evaluating the quantitative trade-offs between equity and efficiency when designing a public policy reform, such as the counterfactual policy experiments that we have considered in the current paper. Future work along these lines should help further improve our understanding of the causes and consequences of income inequality, and is thus both important and promising.

\section{Acknowledgement}

We thank V.V. Chari, Larry Jones, Michele Boldrin, Nobu Kiyotaki, two anonymous referees, and seminar participants at the 2006 Midwest Macroeconomic Meetings, the 2006 Econometric Society North America Summer Meeting, and the 2006 Econometric Society Far Eastern Meeting for helpful comments. We are grateful to Gianluca Violante for providing his data. Liu wishes to thank the Federal Reserve Bank of Minneapolis and the University of Minnesota for their hospitality. The views expressed herein are those of the authors and do not necessarily reflect the views of the Federal Reserve Bank of Minneapolis or the Federal Reserve System.

\section{Appendix}

In this appendix, we describe our data sources and computation methods.

\section{Appendix A: Data}

Our measure of wage inequality (i.e., skill premium) is the ratio of the mean wage for college graduates to that for high-school graduates, where the wages are annualized real wages (in 2002 
dollars). To construct the wage data for different education cohorts, we follow Eckstein and Nagypál (2004) in selecting our sample. The sample includes data for all full-time, full-year workers between ages 18 and 65. The main source of the data is the March Current Population Survey (CPS) from 1962 to 2003. Earlier observations are taken from the 1950 and 1960 Census data.

Our measure of the relative quantity of skilled workers is the ratio of the number of college graduates to that of high-school graduates. These time series are taken from Katz and Autor (1999), who also use the Census and the CPS as their data source. Their sample includes all workers between ages 18 and 65, and we focus on college graduates and high-school graduates.

Our measure of the expenditure for skill accumulation is the current-fund expenditures and educational and general expenditures of degree-granting higher education institutions. The source of the data is National Center for Educational Statistics, Digest of Education Statistics 2003.

\section{Appendix B: Computation}

We solve the model by using the following algorithm:

1. Given $q_{1}=1$, we solve the initial steady state. We save the values of initial consumption $c_{1}$, equipment $k_{e, 1}$, structure $k_{s, 1}$, skilled labor $s_{1}$, fraction of time invested in skill accumulation $e_{1}$, goods invested in human capital $i_{h, 1}$, in equipment $i_{e, 1}$, and in structure $i_{s, 1}$.

2. Given the terminal value of the ISTC series $q_{T}$, we solve the final steady state. We save the values of final-period consumption $c_{T}$, equipment $k_{e, T}$, structure $k_{s, T}$, skilled labor $s_{T}$, fraction of time invested in skill accumulation $e_{T}$, goods invested in human capital $i_{h, T}$, in equipment $i_{e, T}$, and in structure $i_{s, T}$.

3. Through linear interpolations between the initial steady state and the final steady state, we obtain a sequences of each of the eight variables $\left\{c_{t}, k_{e, t}, k_{s, t}, s_{t}, e_{t}, i_{h, t}, i_{e, t}, i_{s, t}\right\}_{t=1}^{T}$. We use these sequences as an initial guess for solving the system of non-linear equations, which consists of equations (3)-(5) and (9)-(13), together with non-negativity constraints on these variables. We have $8 \times T$ equations in this system. We solve this system of equations using standard non-linear numerical methods.

4. We make $T$ sufficiently large so that the transition dynamics between 1949-2000 are not affected by small variations in $T$. 


\section{References}

Acemoglu, D., 1998. Why do new technologies complement skills? Directed technical change and wage inequality, Quarterly Journal of Economics 113(4), 1055-1089.

Acemoglu, D., 2002. Technical change, inequality, and the labor market, Journal of Economic Literature 40(1), 7-72.

Aghion, P., 2002. Schumpeterian growth theory and the dynamics of income inequality, Econometrica 70(3), 855-882.

Ben-Porath, Y., 1967. The production of human capital and the life cycle of earnings, Journal of Political Economy 75(4), 352-365.

Blankenau, W. F., 1999. A welfare analysis of policy responses to the skilled wage premium, Review of Economic Dynamics 2(4), 820-849.

Blankenau, W. F. and Ingram, B. F., 2002. The welfare implications of factor taxation with rising wage inequality, Macroeconomic Dynamics 6(3), 408-428.

Bound, J. and Johnson, G., 1992. Changes in the structure of wages in the 1980's: An evaluation of alternative explanations, American Economic Review 82(3), 371-392.

Chamley, C., 1986. Optimal taxation of capital income in general equilibrium with infinite lives, Econometrica 54(3), 607-622.

Chen, K., İmrohoroğlu, A. and İmrohoroğlu, S., 2006. Japanese saving rate, American Economic Review 96(5), 1850-1858.

Conesa, J. C. and Krueger, D., 1999. Social security reform with heterogeneous agents, Review of Economic Dynamics 2(4), 757-795.

Cummins, J. G. and Violante, G. L., 2002. Investment-specific technical change in the United States (1947-2000): Measurement and macroeconomic consequences, Review of Economic Dynamics 5(2), 243-284.

Domeji, D. and Heathcote, J., 2004. On the distributional effects of reducing capital taxes, International Economic Review 45(2), 523-554.

Denny, M. and Fuss, M., The use of approximation analysis to test for separability and the existence of consistent aggregates, American Economic Review 67, 404-418.

Duffy, J., Papageorgiou, C. and Perez-Sebastian, F., 2004. Capital-skill complementarity? Evidence from a panel of countries, Review of Economics and Statistics 86(1), 327-344.

Eckstein, Z. and Nagypál, E., 2004. The evolution of U.S. earnings inequality: 1961-2002, Federal Reserve Bank of Minneapolis Quarterly Review 28(2), 10-29. 
Gordon, R. J., 1990. The Measurement of Durable Goods Prices. National Bureau of Economic Research Monograph Series, University of Chicago Press, Chicago, IL.

Greenwood, J., Hercowitz, Z. and Krusell, P., 1997. Long-run implications of investment-specific technological change, American Economic Review 87(3), 342-362.

Greenwood, J. and Yorukoglu, M., 1997. 1974, Carnegie-Rochester Conference Series on Public Policy 46, 49-95.

Griliches, Z., 1969. Capital-skill complementarity, Review of Economic and Statistics 51(4), 465468.

Haley, W. J., 1976. Estimation of the earnings profile from optimal human capital accumulation, Econometrica 44, 1223-1238.

Hamermesh, D. S., 1993. Labor Demand. Princeton University Press, Princeton, NJ.

He, H., 2006. Skill premium, schooling decisions, skill-biased technological and demographic change: A macroeconomic analysis, Mimeo, University of Minnesota.

Heckman, J. J., 1976. A life-cycle model of earnings, learning, and consumption, Journal of Political Economy 84(4), S11-S44.

Heckman, J. J., Lochner, L. and Taber, C., 1998. Explaining rising wage inequality: Explorations with a dynamic general equilibrium model of labor earnings with heterogeneous agents, Review of Economic Dynamics 1(1), 1-58.

Hornstein, H. and Krusell, P., 2003. Implications of the capital-embodiment revolution for directed $R \& D$ and wage inequality, Federal Reserve Bank of Richmond Economic Quarterly $89(4), 25-50$.

Katz, L. F. and Autor, D. H., 1999. Changes in the wage structure and earnings inequality. In: Ashenfelter, O., Card D. (Eds.), Handbook of Labor Economics. Elsevier, North-Holland, Vol. 3A, pp. 1463-1555.

Katz, L. F. and Murphy, K. M., 1992. Changes in relative wages, 1963-1987: Supply and demand factors, Quarterly Journal of Economics 107(1), 35-78.

Krusell, P., Ohanian, L. E., Rios-Rull, Jose-Victor and Violante, G. L., 2000. Capital-skill complementarity and inequality: A macroeconomic analysis, Econometrica 68(5), 1029-1053.

Lucas Jr., R. E., 1987. Models of Business Cycles. Basil Blackwell, Oxford.

McGrattan, E. R., 1994. The macroeconomic effects of distortionary taxation, Journal of Monetary Economics 33(3), 573-601.

Mendoza, E. G., Razin, A. and Tesar, L. L., 1994. Effective tax rates in macroeconomics: Cross-country estimates of tax rates on factor income and consumption, Journal of Monetary Economics 34(3), 297-323. 
Stokey, N. L., 1996. Free trade, factor returns, and factor accumulation, Journal of Economic Growth 1(4), 421-447.

Trostel, P. A., 1993. The effect of taxation on human capital, Journal of Political Economy 101(2), $327-350$. 
Table 1.

Calibrated parameter values

\begin{tabular}{lllll}
\hline Preference & $\sigma=1.5$ & $\beta=0.988$ & & \\
Technology & $\theta=0.13$ & $\mu=0.423$ & $\lambda=0.491$ & $\phi=-0.495 \quad \nu=0.79$ \\
Depreciation & $\delta_{s}=0.056$ & $\delta_{e}=0.124$ & $\eta=0.08$ & \\
Skill accumulation & $B=0.349$ & $\xi=0.70$ & $\alpha=0.60$ & \\
Income tax rates & $\tau_{k}=0.397$ & $\tau_{l}=0.277$ & & \\
\hline
\end{tabular}


Table 2.

Initial moment conditions

\begin{tabular}{lcc}
\hline Variable & Model & Data \\
Skill premium & 1.456 & 1.456 \\
$i_{h} / y$ & 0.018 & 0.018 \\
Capital-output ratio & 2.659 & 2.659 \\
Capital income share & 0.267 & 0.267 \\
Skilled-unskilled ratio & 0.288 & 0.288 \\
$c / y$ & 0.769 & 0.812 \\
$k_{e} / k_{s}$ & 0.558 & 0.637 \\
\hline
\end{tabular}


Table 3.

Effects of eliminating capital income taxes

\begin{tabular}{|c|c|c|c|c|}
\hline \multicolumn{5}{|c|}{ A. Sensitivity to $\nu$} \\
\hline$\nu$ & Skill premium & $\mathrm{S}-\mathrm{U}$ ratio & $K_{e^{-S}}$ ratio & Welfare \\
\hline 0.79 (benchmark) & $3.28 \%$ & $23.73 \%$ & $20.02 \%$ & $1.32 \%$ \\
\hline 0.65 & $2.05 \%$ & $14.02 \%$ & $19.13 \%$ & $1.10 \%$ \\
\hline 0.401 & $1.03 \%$ & $6.83 \%$ & $18.25 \%$ & $0.97 \%$ \\
\hline \multicolumn{5}{|c|}{ B. Sensitivity to $\xi$} \\
\hline$\xi$ & Skill premium & $\mathrm{S}-\mathrm{U}$ ratio & $K_{e^{-}} \mathrm{S}$ ratio & Welfare \\
\hline 0.80 & $2.28 \%$ & $29.30 \%$ & $19.72 \%$ & $1.44 \%$ \\
\hline 0.70 (benchmark) & $3.28 \%$ & $23.73 \%$ & $20.02 \%$ & $1.32 \%$ \\
\hline 0.60 & $4.38 \%$ & $18.29 \%$ & $20.42 \%$ & $1.27 \%$ \\
\hline 0.50 & $5.26 \%$ & $14.23 \%$ & $20.74 \%$ & $1.20 \%$ \\
\hline
\end{tabular}


Table 4.

Effects of increasing progressiveness of labor income taxes

\begin{tabular}{lccccc}
\hline$\tau_{s} / \tau_{u}$ & $\begin{array}{c}\text { Skill premium } \\
\text { (after-tax) }\end{array}$ & $\begin{array}{c}\text { Skill premium } \\
(\text { pre-tax) }\end{array}$ & S-U ratio & $K_{e}-\mathrm{S}$ ratio & Welfare \\
1 (benchmark) & $0 \%$ & $0 \%$ & $0 \%$ & $0 \%$ & $0 \%$ \\
1.2 & $-2.25 \%$ & $4.81 \%$ & $-18.32 \%$ & $0.99 \%$ & $-1.24 \%$ \\
1.4 & $-4.31 \%$ & $8.74 \%$ & $-32.48 \%$ & $0.02 \%$ & $-2.68 \%$ \\
1.6 & $-6.25 \%$ & $11.93 \%$ & $-43.77 \%$ & $-1.98 \%$ & $-4.29 \%$ \\
1.8 & $-8.21 \%$ & $14.36 \%$ & $-53.57 \%$ & $-6.05 \%$ & $-6.23 \%$ \\
2.0 & $-10.41 \%$ & $15.83 \%$ & $-63.07 \%$ & $-13.03 \%$ & $-8.88 \%$ \\
\hline
\end{tabular}


Table 5.

Effects of subsidizing human capital investment

\begin{tabular}{lllll}
\hline$\tau_{h}$ & Skill premium & S-U ratio & $K_{e}$-S ratio & Welfare \\
0 (benchmark) & $0 \%$ & $0 \%$ & $0 \%$ & $0 \%$ \\
0.02 & $-0.35 \%$ & $1.28 \%$ & $-0.15 \%$ & $0.08 \%$ \\
0.04 & $-0.69 \%$ & $2.63 \%$ & $-0.29 \%$ & $0.15 \%$ \\
0.06 & $-1.04 \%$ & $4.02 \%$ & $-0.44 \%$ & $0.23 \%$ \\
0.08 & $-1.39 \%$ & $5.47 \%$ & $-0.59 \%$ & $0.30 \%$ \\
0.10 & $-1.74 \%$ & $6.95 \%$ & $-0.74 \%$ & $0.38 \%$ \\
0.12 & $-2.10 \%$ & $8.50 \%$ & $-0.89 \%$ & $0.45 \%$ \\
\hline
\end{tabular}




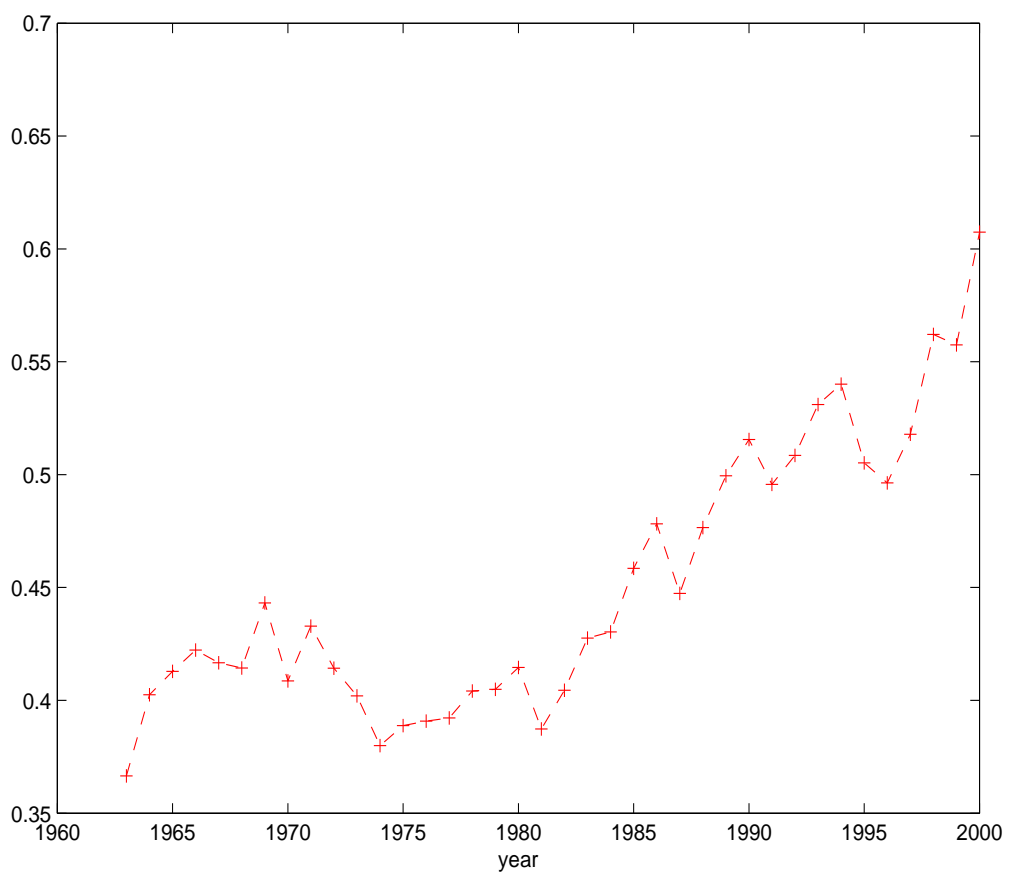

Figure 1:-College wage premium (log units): 1963-2000 


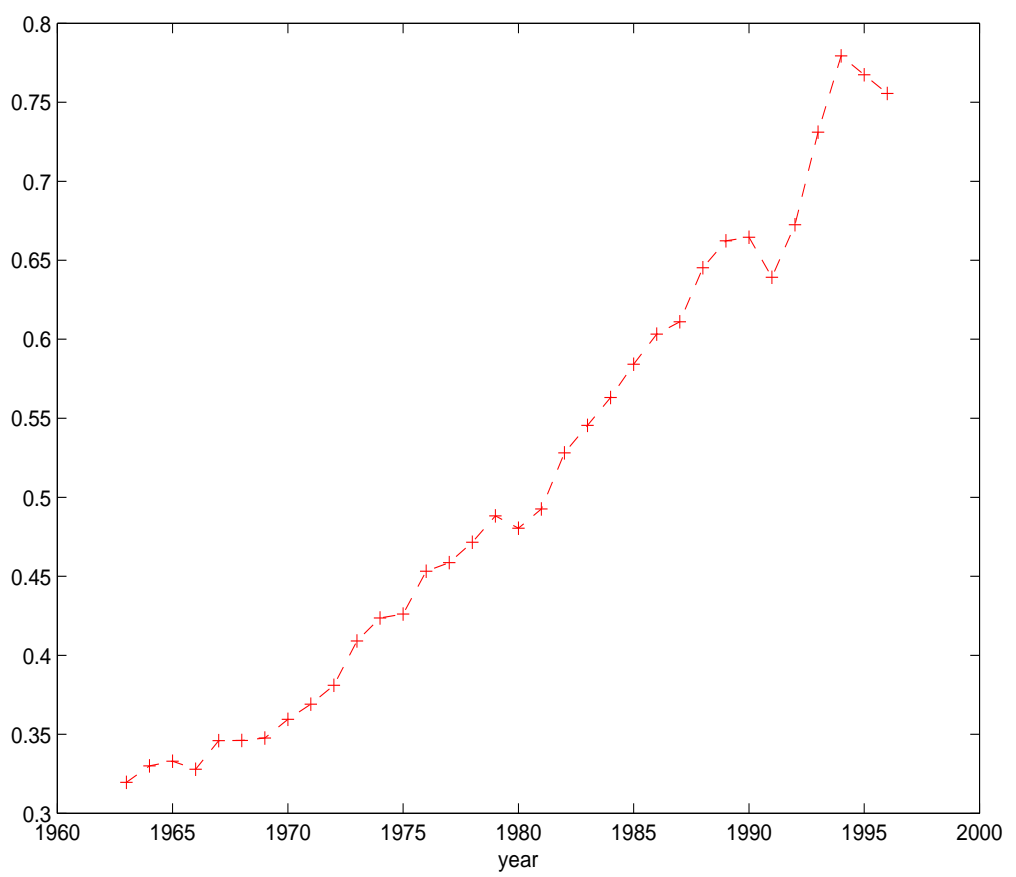

Figure 2:-Relative quantity of college skills: 1963-1996 


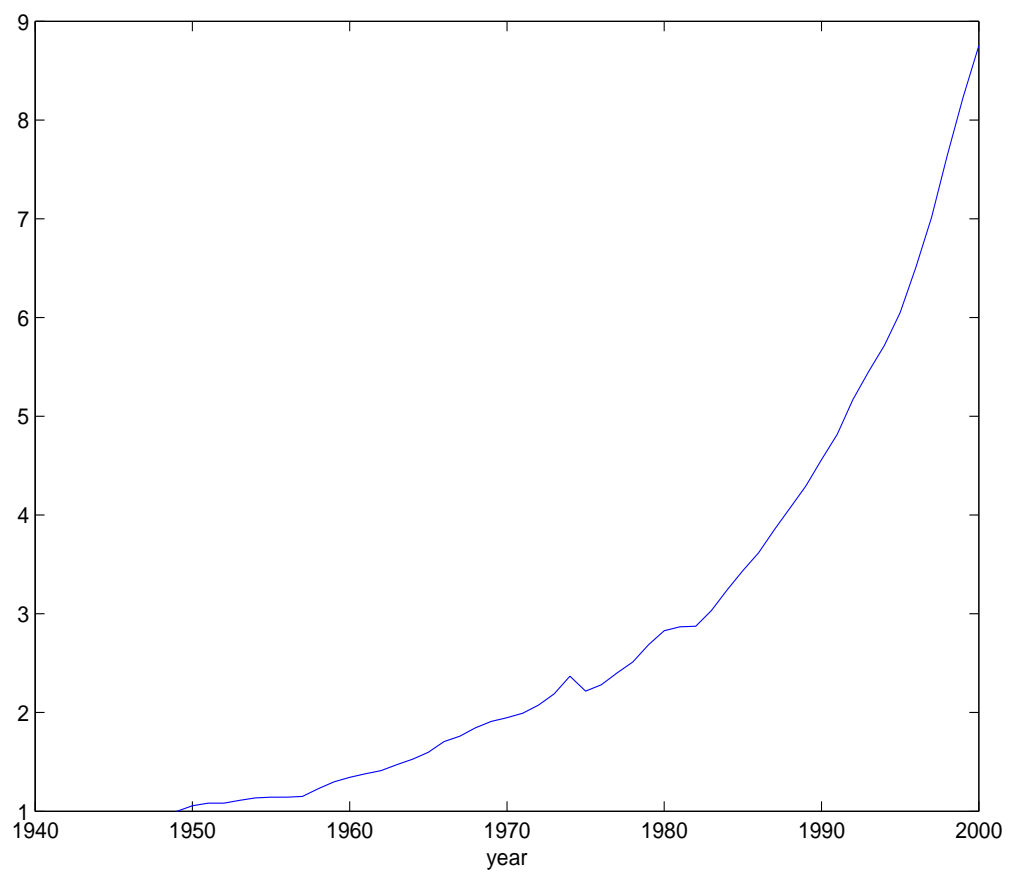

Figure 3:- Investment-specific technological change: 1949-2000 


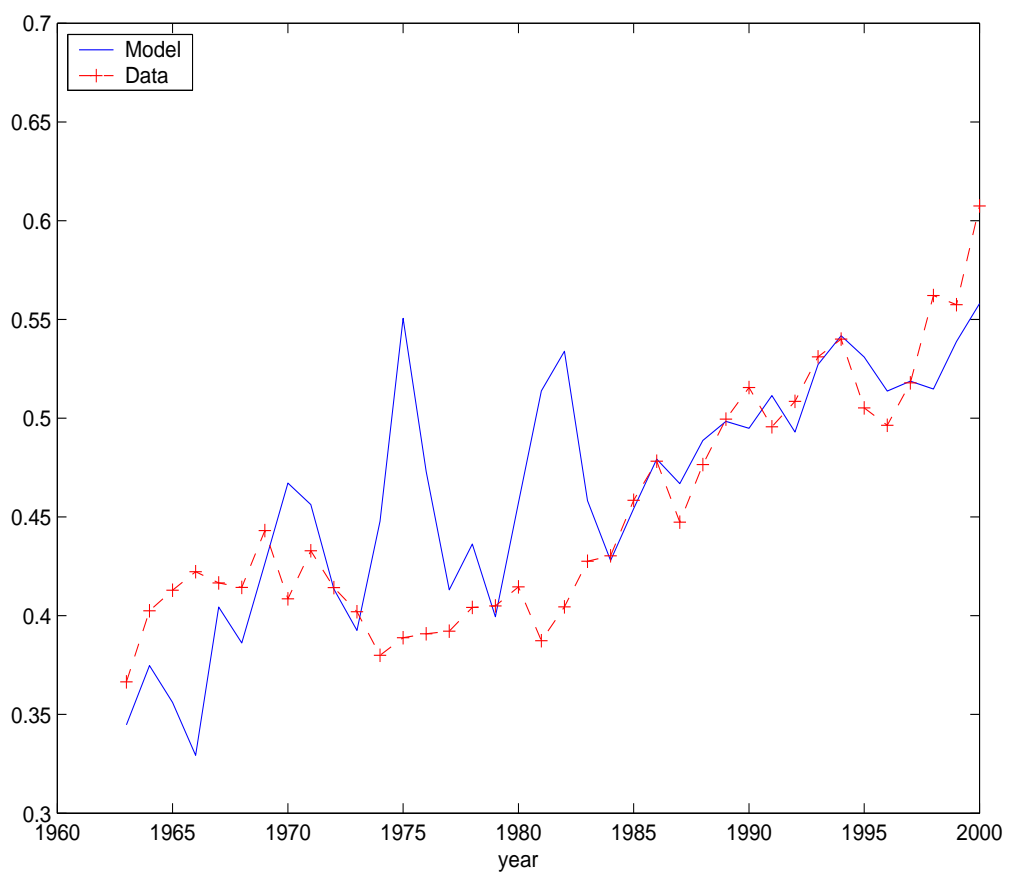

Figure 4:-The skill premium (log units): model vs. data 


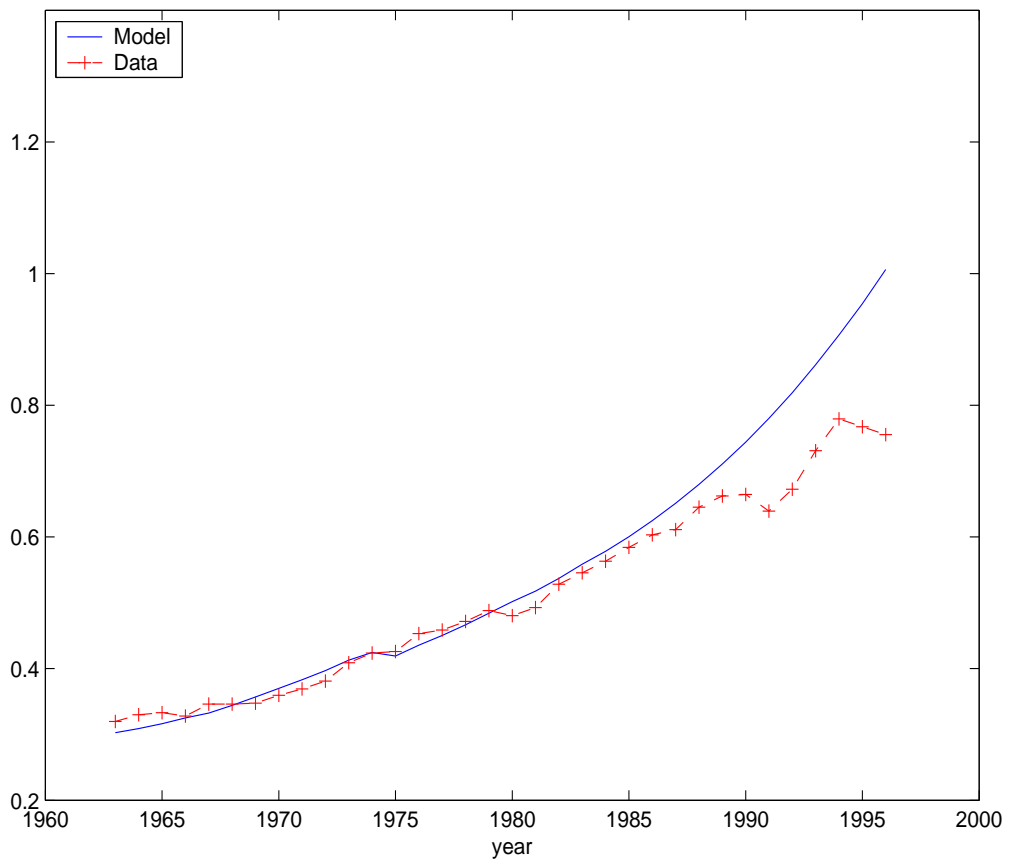

Figure 5:-The skilled-unskilled ratio: model vs. data 


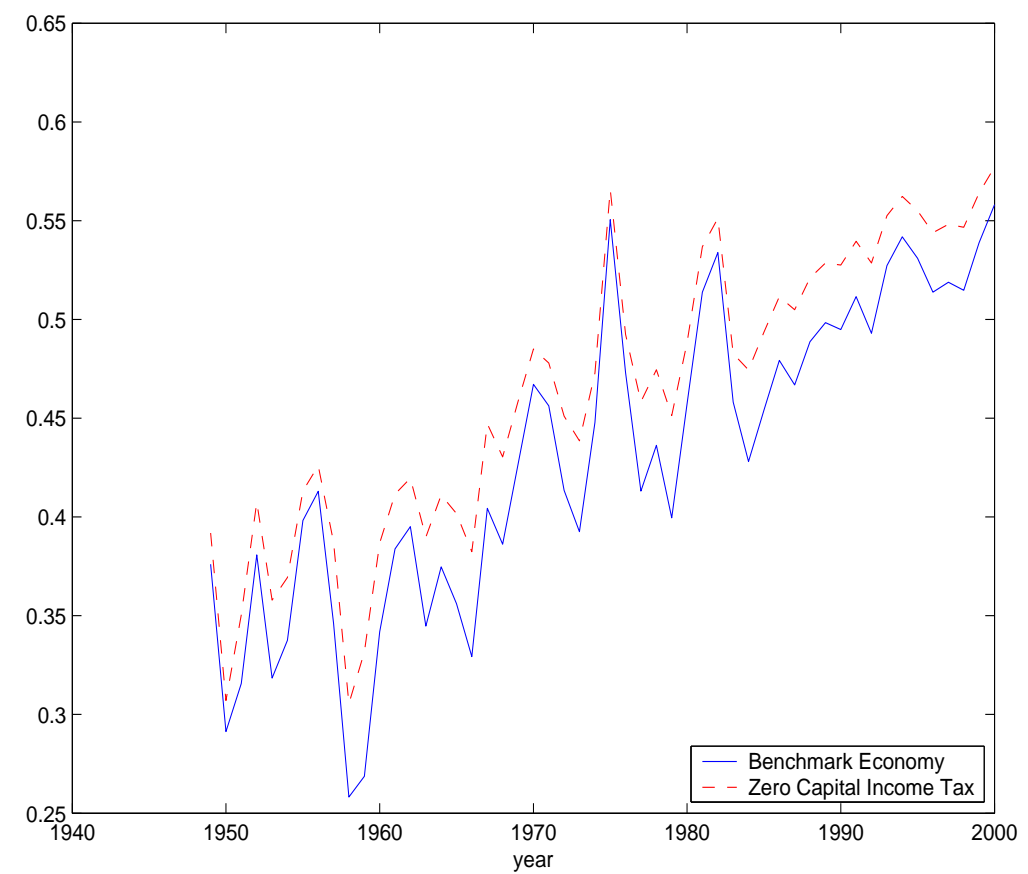

Figure 6:-Effects of capital-tax reform on the skill premium (log units) 

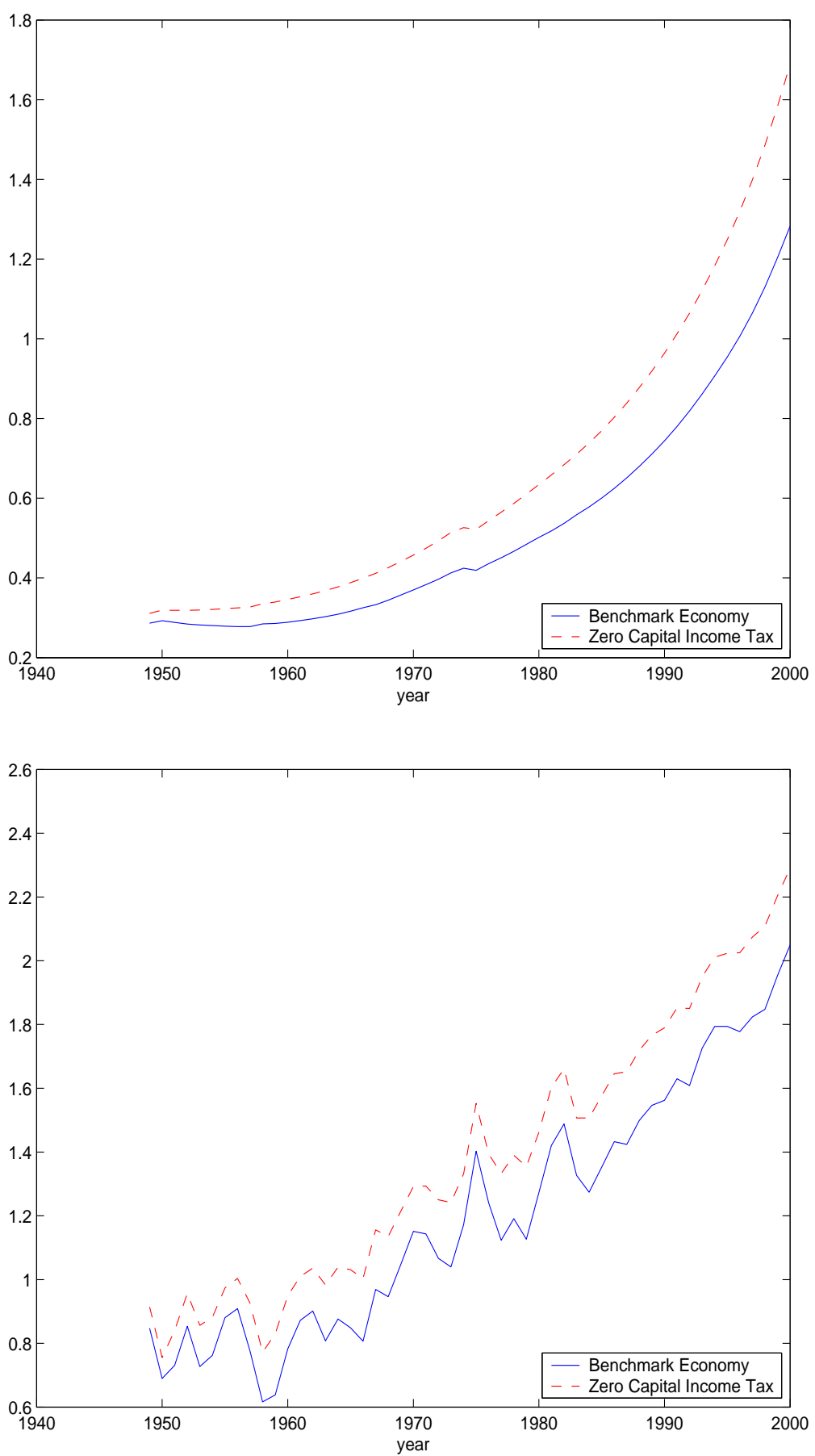

Figure 7:-Effects of capital-tax reform on the skilled-unskilled ratio (top panel) and on the equipment-skill ratio (bottom panel, log units) 